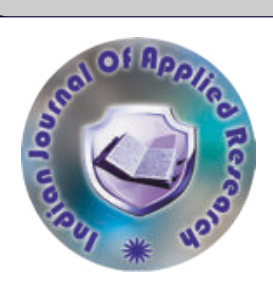

Deepak Jaiswal
Cardiology

\title{
SURGICAL RETRIEVAL OF MIGRATED ENDOVASCULAR STENT FROM THE RIGHT ATRIUM
}

Hrishikesh Parashi

\section{Mohammed} Nadeem Nazim*
Senior Resident, Department of Cardiovascular and thoracic surgery, Grant

Government Medical College, Byculla, Mumbai, Maharashtra, India.

Associate Professor, Department of Cardiovascular and thoracic surgery, Grant

Government Medical College, Byculla, Mumbai, Maharashtra, India.

Senior Resident, Department of Cardiovascular and thoracic surgery, Grant

Government Medical College, Byculla, Mumbai, Maharashtra, India. ${ }^{*}$ Corresponding Author ABSTRACT Central venous stenosis or occlusion occurs in 11-50\% of hemodialysis patients with prior subclavian vein cannulation strategy for selected patents. We report an unusual case of a 60-year-old man on hemodialysis who underwent endovascular stenting for right brachiocephalic vein stenosis and experienced stent migration to the right atrium, requiring surgical treatment.

\section{KEYWORDS : Endovascular stent, stent migration, central venous occlusion, right atrium.}

\section{INTRODUCTION:}

The main predisposing factor of central venous occlusion is previous insertion of a subclavian dialysis catheter, with an incidence rate as high as $50 \%$. ${ }^{1}$ Treatment of central vein occlusion aims to reduce the risk of thrombosis and improve upper extremity oedema as well as

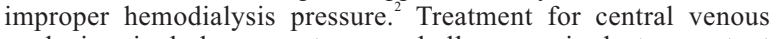
occlusion includes percutaneous balloon angioplasty or stent implantation and the latter is recommended because the balloon dilatation is followed by a rapid incidence of elastic recoil and restenosis. ${ }^{3}$ We report a case of stent migration to the right atrium in a 60 -year-old male patient following endovascular stenting for right subclavian vein stenosis.

\section{CASE REPORT:}

A 60-year male patient with chronic kidney disease and on regular hemodialysis for 11 years referred to our hospital for swelling of face and neck since 3 months. The patient underwent venous angiography revealing occlusion of right brachiocephalic vein. Decision was taken to treat the lesion with endovascular stenting. Under all aseptic precautions right cephalic venous $4 \mathrm{~F}$ and right femoral venous $8 \mathrm{~F}$ access taken, lesion was crossed using Terumo wire and balloon dilated using $10 * 40 \mathrm{~mm}, 14 * 40 \mathrm{~mm}$ balloon and stent-plasty was done using $14 * 40 \mathrm{~mm}$ sinus XL stent. Endovascular stent was deployed in the right brachiocephalic vein. Post procedure fluoroscopy revealed endovascular stent migration to right atrium.

Several attempts were made to snare the stent. A sidewinder catheter over a Terumo wire was used to access the lumen of the stent. The Terumo wire, having passed through the length of the stent, was then snared through the gooseneck. However, attempts were unsuccessful, because even though were able to entrap the stent by snaring it, it was not possible to pull it back through the guiding catheter. The stent was deformed and caught in the right atrium, hence the procedure was terminated to prevent additional damage to the wall of the vena cava and right atrium. (Figure-1) Surgical retrieval of migrated endovascular stent from right atrium done with open heart surgery without extracorporeal circulation. (Figure-2)

\section{DISCUSSION:}

It is estimated that as many as $40 \%$ of patients who undergo subclavian vein catheterisation eventually develop venous stenosis. Complications of stent deployment include obstruction, vessel perforation and migration. Migration is rare but it can be lifethreatening if the stent reaches the heart and pulmonary artery. Migration of stents from the superior vena cava to the innominate vein, pulmonary artery, ${ }^{4}$ right atrium ${ }^{5}$ and right ventricle, ${ }^{6}$ after endovascular stenting for superior vena cava syndrome have been reported previously. Predisposing factors for stent migration include 1) poor choice of lesion 2) inadequate sizing of the stent 3) inaccurate positioning of the stent 4) effect of cardiac motion 5) inaccurate vessel measurement 6) cases in which the disease is expected to be resolved with treatment for example Hodgkin's lymphoma 7) stent deployment system and 8) delivery route.
In case of migrated stent reached to the cardiac structures, it may cause myocardial injury resulting in arrhythmias, injury to valves, and papillary muscles, and rarely myocardial perforation causing hemopericardium and cardiac tamponade. ${ }^{8}$ The migrated stent can be managed either percutaneously or by open surgery. ${ }^{7}$ described four different strategies for endovascular approaches of stent migration into the right atrium. These included: 1) snaring the stent directly, 2) angioplasty balloon-assisted snaring of the stent, 3) guide wireassisted snaring of the stent, and 4) superior vena cava-to-inferior vena cava bridging stent. ${ }^{8}$ Success rates of percutaneous techniques in the management of migrated stents exceed $90 \%{ }^{8,9}$ Open surgical methods to retrieve migrated stents are associated with high morbidity. Although the percutaneous management of migrated stents is highly effective, it is difficult in cases where the stents that have migrated to the right atrium or right ventricle, and these cases may require surgical removal.

Our case was unusual because migration of the stent to the right atrium occurred during the intervention procedure to treat right brachiocephalic vein occlusion. Percutaneous stent removal was attempted, taking into consideration the patient's underlying disease and post-operative complications. Multiple attempts done to retrieve the stent by direct snaring, but had to switch to a surgical procedure because of technical difficulties and the possibility of additional damage to myocardium of right atrium and other anatomical structures of the heart. If a migrated stent is entrapped in the heart and its valvular structure, percutaneous intervention may damage the heart structure and result in a fatal complication. In such cases, surgical removal is a safer and more feasible option, as shown in our case.

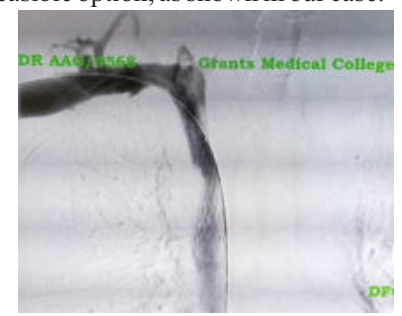

Figure 1- Migrated Endovascular Stent In Right AtriumFluoroscopic Image

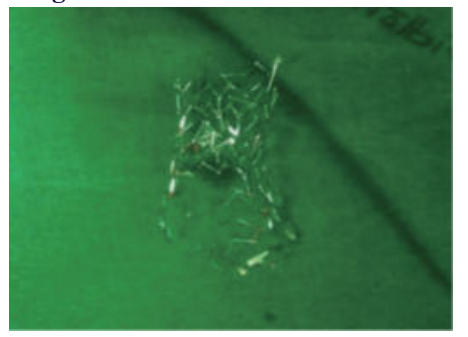

FIGURE 2- The retrieved stent 
REFERENCES:

1. Schillinger F, Schillinger D, Montagnac R, Milcent T. Post catheteri-sation vein stenosis in haemodialysis: comparative angiographic study of 50 subclavian and 50 internal in haemodialysis: comparative angiographic study of 50 .
jugular accesses. Nephrol Dial Transplant 1991;6:722-4.

2. NKF-DOQI clinical practice guidelines for hemodialysis adequacy. Nation $\neg$ al Kidney Foundation. Am J Kidney Dis 1997;30:S15-66.

3. Kovalik EC, Newman GE, Suhocki P, Knelson M, Schwab SJ. Cor $\neg$ rection of central venous stenoses: use of angioplasty and vascular Wallstents. Kidney Int 1994;45:117781. Surrat R, Picus D, Hicks M, Darcy MD, Kleinhoffer M, Jendrisak M:The importance of preoperative evaluation of the subclavianvein in dialysis planning. AJR 1991, 156:623-625.

4. Gray RJ, Dolmatch BL, Horton KM, Romolo JL, Zarate AR. Mi-gration of Palmaz stents following deployment for venous stenoses related to hemodialysis access. J Vasc Interv Radiol 1994:5:117-20.

5. Bartorelli AL, Fabbiocchi F, Montorsi P, Loaldi A, Tamborini G, Sganzerla P. Successful transcatheter management of Palmaz Stent emboli-zation after superior vena cava transcatheter management of Palmaz Stent emm
stenting. Cathet Cardiovasc Diagn 1995;34:162-6.

6. Poludasu SS, Vladutiu P, Lazar J. Migration of an endovascular stent from superior vena cava to the right ventricular outflow tract in a patient with superior vena cava syndrome. Angiology 2008;59:114-6.

7. Taylor JD, Lehmann ED, Belli AM, Nicholson AA, Kessel D, Rob-ertson IR, Pollock JG, Morgan RA. Strategies for the management of SVC stent migration into the right atrium. Cardiovasc Intervent Radiol 2007;30:1003-9.

8. Gabelmann A, Kramer S, Gorich J. Percutaneous retrieval of lost or misplaced intravascular objects. AJR Am J Roentgenol 2001;176:1509-13.

9. Slonim SM, Dake MD, Razavi MK, Kee ST, Samuels SL, Rhee JS, Semba CP. Management of misplaced or migrated endovascular stents. J Vase Interv Radiol 1999;10:851-9. 